\title{
THE SUBJECT'S PERSPECTIVE OBJECTION TO EXTERNALISM AND WHY IT FAILS
}

\author{
Perry HENDRICKS
}

\begin{abstract}
The subject's perspective objection (SPO) is an objection against externalist theories of justification, warrant, and knowledge. In this article, I show that externalists can accommodate the SPO while remaining externalist. So, even if the SPO is successful, it does not motivate internalism, and the primary motivation for internalism has been lost. After this, I provide an explanation for why so many people find cases that motivate the SPO convincing.
\end{abstract}

KEYWORDS: subject's perspective objection, externalism, internalism, justification

\section{Introduction}

The subject's perspective objection (SPO) is commonly used to motivate internalist theories of justification; indeed, Michael Bergmann portrays it as the main reason for endorsing internalism. ${ }^{1}$ Variations of the SPO have appeared in, for example, Laurence Bonjour, ${ }^{2}$ Keith Lehrer, ${ }^{3}$ Paul Moser, ${ }^{4}$ and Bruce Russell. ${ }^{5}$ In this article, I explain internalism, externalism, and the SPO. Next, I show that one can accommodate the SPO while remaining an externalist, meaning that the SPO doesn't motivate internalism. Therefore, the main motivation for internalism has been lost, and the case for internalism is substantially weakened. After this I show that the SPO rests on a false premise, and hence does not threaten externalism.

${ }^{1}$ See Michael Bergmann, Justification Without Awareness (New York: Oxford University Press, 2006).

2 Laurence Bonjour, "Externalist Theories of Empirical Knowledge," Midwest Studies in Philosophy 5, 1980: 53-73 and Laurence Bonjour The Structure of Empirical Knowledge (Cambridge: Harvard University Press, 1985).

${ }^{3}$ Keith Lehrer, Theories of Knowledge (Nashville: Westview Press 1990) and Keith Lehrer "Proper Function and Systematic Coherence," in Warrant in Contemporary Epistemology: Essays in Honor of Plantinga's Theory of Knowledge, ed. Jonathan Kvanvig (Pennsylvania: Rowman and Littlefield, 1996): 25-45.

${ }^{4}$ Paul Moser, Empirical Justification (Dordrecht Holland: D. Reidel, 1985).

5 Bruce Russell, "The Problem of Evil and Replies to Some Important Responses," European Journal of Philosophy of Religion 10, 3 (2018): 105-131.

(C) LOGOS \& EPISTEME, XI, 3 (2020): 323-331 
Perry Hendricks

Finally, I provide a diagnosis for why people find the cases that motivate the SPO convincing.

\section{The Subject's Perspective Objection}

In epistemology, internalism and externalism are the dominant positions. ${ }^{6}$ Internalists hold, roughly, that if $S$ is justified in believing $\mathrm{p}$, then $\mathrm{S}$ is (actually or potentially) aware of what justifies her belief that p. Externalists deny this: externalists hold that $\mathrm{S}$ can be justified in believing that p even if she isn't (actually or potentially) aware of what justifies her belief that p. Many have objected to externalism on the grounds that if $\mathrm{S}$ is not (actually or potentially) aware of what justifies her belief then, even if it meets externalist conditions for justification, the truth of it will appear accidental to her. However, if S's belief appears accidentally true to her, then she isn't justified in believing it. Hence, externalism is false and we should endorse internalism.

Laurence Bonjour, perhaps the most famous proponent of this style of objection, uses the following story to motivate internalism:

NORMAN: Norman, under certain conditions that usually obtain, is a completely reliable clairvoyant with respect to certain kinds of subject matter. He possesses no evidence or reasons of any kind for or against the general possibility of such a cognitive power, or for or against the thesis that he possesses it. One day Norman comes to believe that the President is in New York City, though he has no evidence either for or against his belief. In fact the belief is true and results from his clairvoyant power under circumstances in which it is completely reliable. $^{7}$

In NORMAN, externalist conditions for justification are met, yet Norman lacks justification. Hence, externalism is false. As Bonjour tells the story, we are supposed to understand Norman as not having positive reasons to doubt that veracity of his belief; he doesn't have a defeater for his belief. ${ }^{8}$ However, just one page later, Bonjour suggests that

[I]t becomes quite difficult to understand what Norman himself thinks is going on. From his standpoint, there is apparently no way in which he could know the President's whereabouts... Why isn't the mere fact that there is no way, as far as

\footnotetext{
${ }^{6}$ Though, they are not exhaustive. Michael Bergmann argues that a position he calls 'mentalism' is neither internalist nor externalist. That said, I will treat the positions as exhaustive in this article. See Michael Bergmann, Justification Without Awareness (New York: Oxford University Press, 2006).

${ }^{7}$ Bonjour, The Structure, 41.

${ }^{8}$ Bonjour, The Structure, 40-41.
} 
The Subject's Perspective Objection to Externalism and Why it Fails

he knows, for him to have obtained [information about the president] sufficient reason for classifying this belief as an unfounded hunch and ceasing to accept it? ${ }^{9}$

So, Bonjour asks us to understand Norman's belief as being akin to an unfounded hunch. If we are to think of Norman's belief as being akin to an unfounded hunch, then it seems that we are attributing to Norman a psychological property, namely the psychological property of his belief appearing to him as an unfounded hunch. ${ }^{10}$

There is textual evidence for interpreting Bonjour in this way: he says that "[f]rom [Norman's] subjective perspective, it is an accident that the belief is true."11 In other words, the belief appears to Norman to be accidentally true. ${ }^{12}$ Thus, it appears that a (negative) psychological property, that of appearing accidentally true, accompanies Norman's belief. However, if a belief appears accidentally true to a person, then she has a defeater for her belief (more on this later), and this explains why NORMAN threatens externalism: externalist conditions for justification obtain yet his belief is defeated and therefore unjustified. But this explicitly conflicts with Bonjour's urging that we should understand everything from Norman's perspective to be just fine; he doesn't want us to understand Norman as having a defeater. It appears, therefore, that Bonjour is inconsistent in his portrayal of Norman. What should we do here? I suggest that we understand Bonjour as saying that Norman does indeed have a defeater. This is because Norman's belief appearing accidentally true to him is what does the work in NORMAN: if Norman's belief doesn't appear accidentally true to him, then it's not at all clear that NORMAN is a counterexample to externalism or motivates internalism. ${ }^{13}$

Another advantage of this interpretation is that it fits well with other, similar objections to externalism, such as Lehrer's Mr. Truetemp case. ${ }^{14} \mathrm{Mr}$. Truetemp has, unbeknownst to him, a device implanted in him that produces

\footnotetext{
${ }^{9}$ Bonjour, The Structure, 42.

${ }^{10}$ An unfounded hunch differs from other beliefs in how it feels: it feels like a hunch, as opposed to a normal belief.

${ }^{11}$ Bonjour, The Structure, 43.

12 This interpretation is forced on us by the fact that Bonjour connects the accidental appearance of Norman's belief to his subjective perspective.

${ }^{13}$ Bonjour says "[h]ow [can external conditions] justify Norman's belief? From his subjective perspective, it is an accident that the belief is true. And the suggestion here is that the rationality or justifiability of Norman's belief should be judged from Norman's own perspective." (The Structure, 42-43) This strongly suggests that the appearance of accidentality, which is a defeater for Norman, is what does the work in NORMAN.

${ }^{14}$ Lehrer, "Proper Function."
} 
Perry Hendricks

accurate beliefs about the temperature in such a way that externalist conditions for justification are satisfied. However, Lehrer says, Mr. Truetemp "has no idea whether [his belief about the temperature] is correct and he is totally mystified by the existence of it,"15 and hence externalist conditions for justification are insufficient: Mr. Truetemp's mystification acts as a defeater for his belief, making it unjustified. ${ }^{16}$ Lehrer's basic point appears to be the same as Bonjour's: if only externalist conditions for justification are met, the subject's belief will appear accidental, and this defeats her belief, making it unjustified.

Michael Bergmann has usefully summarized the above style of objection as follows:

The Subject's Perspective Objection (SPO): If [a] the subject holding a belief isn't aware of what that belief has going for it, then [b] she isn't aware of how its status is any different from a stray hunch or an arbitrary conviction. [c] From that we may conclude that from her perspective it is an accident that her belief is true. And that implies that it isn't a justified belief. ${ }^{17}$

[a] is just a case in which internalist conditions of justification don't obtain, [b] is what Bonjour (and Lehrer) assert follows from [a], and [c], thinks Bonjour (and Lehrer), follows from [b]. So, the SPO maps onto what Bonjour is arguing with NORMAN and the inferences he makes. Thus, I will treat the SPO as representative of NORMAN (as well as Mr. Truetemp and other similar cases). The SPO, according to Bergmann, is the main motivation for internalism. So, if it can be shown that it doesn't actually motivate internalism, then internalism is in trouble. In what follows, I will try to show just this.

\section{An Externalist Solution to the SPO}

So, the main motivation for internalism about justification is the SPO. In this section, I will argue that the SPO doesn't support internalism; rather, it merely supports a no-defeaters condition (explained below). As we saw above, part of the SPO, namely [c], is the claim that S's belief appears accidentally true, and this, claims the SPO, implies that the belief is not justified. We may put this as:

ACCIDENT: If S's belief that $\mathrm{p}$ appears accidentally true to $\mathrm{S}$, then she has a defeater for $\mathrm{p}$.

\footnotetext{
${ }^{15}$ Lehrer, "Proper Function," 32, emphasis mine.

${ }^{16}$ For other similar examples, see Lehrer, Theories of Knowledge, Moser, Empirical Justification, and Russell, "The Problem."

${ }^{17}$ Bergmann, Justification, 12.
} 
The Subject's Perspective Objection to Externalism and Why it Fails

ACCIDENT threatens externalist theories of justification. This is because, according to the SPO, if only externalist conditions for justification are satisfied by $\mathrm{S}$, the truth of her beliefs will appear accidental and hence will be defeated. And this means that her beliefs are unjustified.

While ACCIDENT is not incontestable, I will grant its truth here to see where it takes us. Does ACCIDENT conflict with externalism? Not obviously. What is required to avoid the trouble brought about by ACCIDENT is the following thesis:

NO DEFEATERS: S's belief that $\mathrm{p}$ is justified only if $\mathrm{S}$ does not have any (undefeated) defeaters for her belief that $\mathrm{p}$.

So, the SPO entails ACCIDENT, and ACCIDENT shows that the correct theory of justification must be able to accommodate NO DEFEATERS. Therefore, if the SPO motivates internalism, it must be that in order to satisfy NO DEFEATERS, S must be aware of that which justifies her belief that $\mathrm{p}$ (i.e. it must be that only internalism can accommodate NO DEFEATERS). But, of course, S doesn't need to be aware of that which justifies her belief in order to satisfy NO DEFEATERS; to not have a defeater for $\mathrm{p}, \mathrm{S}$ needs to lack a mental state (whatever belief of hers is acting as a defeater for $\mathrm{p}$ ), not have a mental state (i.e. an awareness of that which justifies her belief that $\mathrm{p}$ ).

It should be clear, then, that externalism is compatible with, can accommodate, NO DEFEATERS. To illustrate this, suppose one is a proper functionalist about justification:

PROPER FUNCTIONALISM: $\mathrm{S}$ is justified in her belief that $\mathrm{p}$ if and only if (i) $\mathrm{S}$ believes $\mathrm{p}$, (ii) $\mathrm{p}$ is true, (iii) $\mathrm{S}$ 's belief that $\mathrm{p}$ was produced by properly functioning cognitive faculties that are successfully aimed at producing true beliefs, and (iv) $\mathrm{S}$ is situated in an appropriate cognitive environment. ${ }^{18}$

For the adherent of PROPER FUNCTIONALISM to accommodate NO DEFEATERS, she need only add the following condition to PROPER FUNCTIONALISM:

(v) S does not have any (undefeated) defeaters for her belief that $\mathrm{p}$.

\footnotetext{
${ }^{18}$ For statements and defenses of PROPER FUNCTIONALISM, see Alvin Plantinga, Warrant and Proper Function (New York: Oxford University Press, 1993), Alvin Plantinga, Warrant: The Current Debate (New York: Oxford University Press, 1993), and Alvin Plantinga, Warranted Christian Belief (New York: Oxford University Press, 2000), Bergmann, Justification, and Kenneth Boyce and Alvin Plantinga, "Proper Functionalism," in The Continuum Companion to Epistemology, ed. Andrew Cullison (London: Continuum, 2012): 124-141.
} 
Perry Hendricks

But, of course, (v) doesn't (at least obviously) entail that $S$ is (potentially or actually) aware of that which justifies her belief that p; it merely means that she doesn't have a reason to doubt the reliability of p's source. (Indeed, Bergmann adds this condition to PROPER FUNCTIONALISM. ${ }^{19}$ ) Hence, NO DEFEATERS is compatible with externalism. That is, NO DEFEATERS is neutral in respect to the internalism-externalism debate: all the SPO shows is that NO DEFEATERS must be included in the correct theory of justification, but NO DEFEATERS can be added to both internalist and externalist theories of justification. Therefore, the SPO doesn't motivate internalism: the main motivation for internalism is not a motivation for it at all. So, if the SPO really is the main motivation for internalism, then internalism is in bad shape indeed.

\section{Objection: The SPO Does Motivate Internalism}

One might think that I have moved too quickly here: while NO DEFEATERS is neutral in respect to internalism and externalism, the SPO provides a way to link NO DEFEATERS to internalism. This is because in the SPO [a] entails $[\mathrm{b}]$ and $[\mathrm{b}]$ entails [c], and hence if S's belief that $p$ doesn't meet internalist conditions for justification, then $\mathrm{p}$ will always appear accidentally true to $\mathrm{S}$, and hence $\mathrm{S}$ will always have a defeater for $\mathrm{p}$. Therefore, if NO DEFEATERS is part of an externalist theory of justification, $\mathrm{S}$ will never satisfy $\mathrm{it}^{20}$ and hence will never be justified by externalist standards. So, the only way to be a realist about justification, to hold that we are actually justified in some of our beliefs, is to assume that internalist conditions for justification are met. ${ }^{21}$ Call this THE ARGUMENT. We my put it as follows:

1) If [a] the subject holding a belief isn't aware of what that belief has going for it, then [b] she isn't aware of how its status is any different from a stray hunch or an arbitrary conviction. (from the SPO)

2) If [b] S isn't aware of how its status is any different from a stray hunch or arbitrary conviction, then [c] from her perspective it is an accident that her belief is true. ${ }^{22}$ (from the SPO)

3) Therefore, if [a] the subject holding a belief isn't aware of what that belief has going for it, then $[c]$ from her perspective it is an accident that

\footnotetext{
${ }^{19}$ More precisely, he adds a no believed defeaters condition (Bergmann, Justification, 163-168).

${ }^{20}$ Here, I am supposing that internalist conditions for justification are not met; only externalist conditions are.

${ }^{21}$ This is interesting since externalism is usually cited as preserving commonsense views about justification.

${ }^{22}$ For ease of read, I have slightly modified [b] and [c].
} 
The Subject's Perspective Objection to Externalism and Why it Fails her belief is true. (from (1) and (2))

4) If a belief doesn't meet internalist conditions for justification, then [a]. (from the definition of internalism)

5) Therefore, if a belief doesn't meet internalist conditions for justification, then [c]. (from (3) and (4))

6) If [c], then the belief has a defeater and is not justified. (from ACCIDENT and NO DEFEATERS)

7) Therefore, any belief that doesn't satisfy internalist conditions for justification is not justified. (from (5) and (6))

The upshot of THE ARGUMENT is that even if the externalist adds NO DEFEATERS to her criteria of justification, she will never be able to satisfy it; that is, if $\mathrm{S}$ is not aware of that which justifies her belief that $\mathrm{p}$ (i.e. if she doesn't satisfy internalist conditions for justification), then, per the SPO, she will never satisfy NO DEFEATERS and hence will never have pure externalist justification. ${ }^{23}$ Therefore, since the SPO rules out (pure) externalist justification ever obtaining, it motivates internalism.

\subsection{Response: THE ARGUMENT is Unsound}

No doubt THE ARGUMENT, if sound, shows that the SPO supports internalism. However, I will show that both premises (1) and (2) of THE ARGUMENT are false.

The fundamental problem with premise (1) is that it only takes into account awareness of positive aspects of beliefs. While the externalist holds that $\mathrm{S}$ can be justified even if she is not aware of its positive aspects and their relevance to her belief, she - if she endorses NO DEFEATERS - will also hold that $\mathrm{S}$ is not justified if her belief has a(n undefeated) defeater. If a belief of S's has a defeater, then $\mathrm{S}$ can recognize that it does and distinguish it from other, undefeated beliefs. This means that $\mathrm{S}$ can recognize that arbitrary convictions or stray hunches are epistemically bad and have defeaters, and this enables her to distinguish them from other beliefs of hers that do not have defeaters. So, if S's belief that $\mathrm{p}$ meets the externalist conditions for justification and NO DEFEATERS, then she will be able to distinguish $\mathrm{p}$ from another belief $\mathrm{p}^{*}$ that has a defeater (e.g. because it is a 'stray hunch' or 'arbitrary conviction'). In other words, $\mathrm{S}$ can distinguish defeated beliefs (e.g. a stray hunch) from undefeated beliefs, and hence premise (1) is false.

${ }^{23}$ By "pure externalist justification" I mean justification that results from purely externalist conditions, such as PROPER FUNCTIONALISM. 
Perry Hendricks

Crucially, $\mathrm{p}$ appearing accidentally true from S's perspective is a psychological property; therefore, in considering whether premise (2) is true, we need to know whether [b] necessitates a certain psychological property. [b], in essence, states that any belief of S's that is in the epistemic class of hunches and arbitrary convictions will have the psychological property of appearing accidental from her perspective. However, once we recognize this, premise (2) seems highly dubious. Consider a 'stray hunch.' One might have a stray hunch that $\mathrm{X}$ is true, and when she finds out it's true, she will say "I knew it! I told you so!," in which case the truth of X didn't appear accidental to S. ${ }^{24}$ (More generally, it is dubious to suppose the psychological state appearing accidental to $S$ is necessarily connected with S's belief being akin to a stray hunch.) So the truth of a stray hunch need not (necessarily) appear accidental to S. But perhaps I have overlooked the fact that it is a stray hunch: one might claim that to have a stray hunch just is for one to have a hunch that, after turning out true, appears accidental to its subject. If that is how we are to read $[b]$, then the objector is correct. However, if we read [b] that way, then $[c]$ reduces to $[b]$. Since $[c]$, on this interpretation, is just a restatement of [b], premise (2) is superfluous, and we are left with only the inference from [a] to [b] in premise (1), which we have already seen is false. So, either premise (2) is false, or it reduces to premise (1) which is false. Either way, THE ARGUMENT is unsound.

The upshot of this section is that the SPO is fundamentally flawed. Hence, even if the SPO entailed internalism, it would not help internalists since it relies on false premises.

\section{Why do so Many Think the SPO is Plausible?}

The reason the SPO strikes many as being so plausible, I contend, is that the examples that are usually given to motivate it make use of cognitive faculties that humans are predisposed to regard as dubious. Thus, the deck has been rigged against externalism. The formula of the SPO is this:

FORMULA: (i) $\mathrm{S}$ has cognitive faculty $\mathrm{F}$, (ii) $\mathrm{S}$ forms a belief by way of $\mathrm{F}$, (iii) $\mathrm{F}$ reliably produces true beliefs, and (iv) $\mathrm{S}$ has no way of confirming (or never has confirmed) (iii).

Typically, condition (i) of FORMULA refers to a F that humans don't have. ${ }^{25}$ It is then argued that in FORMULA externalist conditions of justification are met,

\footnotetext{
${ }^{24}$ This is because we don't claim to know things that appear accidentally true. Instead, we might say "that was lucky."

${ }^{25}$ Norman is a clairvoyant (Bonjour, The Structure), Mr. Truetemp has a temperature faculty (Lehrer, "Proper Function"), Mr. Truenorth has a faculty that produces beliefs about what
} 
The Subject's Perspective Objection to Externalism and Why it Fails

but S's belief produced by F isn't justified since it is, in some sense, bizarre. And hence externalism is false. However, we can fill out FORMULA in a way that doesn't undermine externalism. Consider:

NORMA: Norma is a regular human being that is dropped off into the wild by her parents when she is a baby. By divine provision, she grows up into adulthood without encountering another living creature. On her 18th birthday, a group of hikers stumble upon Norma. Upon seeing them, her 'theory of mind'26 produces various beliefs about their (the hiker's) mental states (e.g. that thing looks concerned, that thing is trying to communicate with me, etc.). She is unaware she has a theory of mind, has never tested it or used it before, and doesn't know the typical cognitive faculties that her species has.

I suspect that many will be inclined to attribute Norma justification. But, like NORMAN (Mr. Truetemp, etc.), NORMA is just a filled out version of FORMULA. This shows us that whether FORMULA supports the SPO is contingent on what faculty is instantiated in F: if $\mathrm{F}$ isn't a faculty a normal human possesses, it (may) elicit(s) the intuition that $\mathrm{S}$ lacks justification. However, if $\mathrm{F}$ is a normal human faculty, then it (may) elicit(s) the intuition that $\mathrm{S}$ is justified. This shows us that what's doing work in the SPO is not the fact that externalist conditions are met, but that the faculty that produces the belief in question isn't typically had by human beings. So, to hold that these cases support the SPO is to affirm a form of justificatory imperialism: it entails that beliefs produced by cognitive faculties that are not had by humans do not have justification. The grounding of the SPO, therefore, appears to be in a prejudice against non-human-like cognitive faculties. So, those who are dubious about such a human-centered view of justification have further reason to reject the SPO. ${ }^{27}$

direction one is facing (Russell, "The Problem"), and so on.

${ }^{26}$ Theory of mind is a cognitive faculty responsible for producing beliefs about the mental states of other creatures. See e.g. chapter 1 of Justin Barrett, Why Would Anyone Believe in God? (Maryland: AltaMira Press, 2004), chapters 1-3 of Justin Barrett, Cognitive Science, Religion, and Theology: From Human Minds to Divine Minds. (Pennsylvania: Templeton Press, 2011), and Justin Barrett, Born Believers: The Science of Children's Religious Belief. (New York: Free Press, 2012), N. Knight, P. Sousa, J. Barrett, and S. Atran, "Children's attributions of beliefs to humans and God," Cognitive Science 28 (2004): 117-126, R.A. Richert and P.L. Harris, "Dualism revisited: Body vs. mind vs. soul," Journal of Cognition and Culture 8 (2008): 99-115, and Adam Waytz, Kurt Gray, Nicholas Epley, and Daniel M. Wegner "Causes and consequences of mind perception," Trends in Cognitive Sciences 8 (2010): 383-388.

27 For comments on this article, thanks to Michael Bergmann. And thanks especially to G.L.G.-Colin Patrick Mitchell—for particularly insightful comments. 